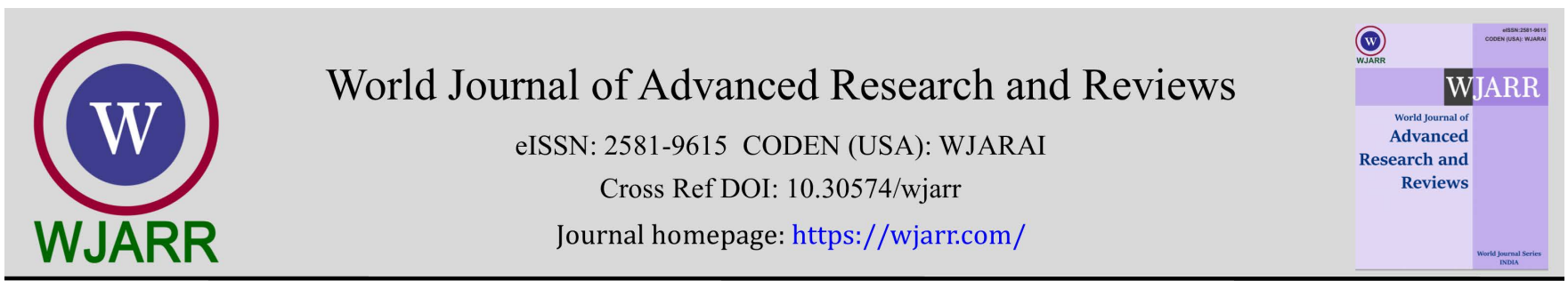

(RESEARCH ARTICLE)

Check for updates

\title{
Enumerate chlorogenic acid in different forms of coffee by simple high performance thin layer chromatographic method
}

\author{
Swati Bhattacharyya 1, Alok Kumar Hazra 2, BantiChakraborty 3, Tapas Kumar Sur ${ }^{4}$ and AvijitSaha 4,5,* \\ ${ }^{1}$ Department of Pharmacology, R.G. Kar Medical College, Kolkata, India. \\ ${ }^{2}$ RKM Vivekananda Educational \& Research Institute, Kolkata, India. \\ ${ }^{3}$ RKM Vivekananda Educational \& Research Institute, Kolkata, India. \\ ${ }^{4}$ Multidisciplinary Research Unit, R.G. Kar Medical College, Kolkata, India. \\ ${ }^{5}$ Department of Biochemistry, R.G. Kar Medical College, Kolkata, India.
}

World Journal of Advanced Research and Reviews, 2021, 09(02), 120-126

Publication history: Received on 12 January 2021; revised on 14 February 2021; accepted on 16 February 2021

Article DOI: https://doi.org/10.30574/wjarr.2021.9.2.0051

\begin{abstract}
The health benefit of coffee consumption mainly depends on chlorogenic acid (CGA), one of its major active phenolic constituent. CGA have several biological properties like anticancer, antihypertensive, hepatoprotective, neuroprotective, renoprotective, antimicrobial etc. It is assumed that different forms of coffee contains different amount of CGA. In this regards, we developed and validated a simple and cost effective chromatographic technique to identify and quantify CGA in green coffee, roasted coffee and branded instant coffee available in Indian market.
\end{abstract}

Keywords: Coffee; Chlorogenic acid; HPTLC; UV-VIS spectroscopy

\section{Introduction}

Coffee is one of the most widely consumed beverages worldwide. So far, more than eighty coffee species (genus: Coffea, family: Rubiaceae) have been identified but only two are commercially important - Coffeaarabica(Arabica coffee) and Coffeacanephora(Robusta coffee). 70\% of global coffee market is dominant by Arabica coffee [1]. Green coffee beans are the unprocessed or unroasted seeds of coffee berries and rich in chlorogenic acid (CGA) and its related compound such as quinic acid, p-coumaric acid, feluric acid and caffeic acid [2]. Besides CGA, coffee seeds contain caffeine, diterpenes, trigonelline etc. CGA is a phenolic compound with antioxidant activity and high bioavailability in human [3]. Extensiveresearches have been conducted to find out the health benefit of coffee consumption. Revuelta-Iniesta and AlDujaili (2014) reported that consumption of green coffee reduces hypertension by influencing $11 \beta$-HSD1 enzyme activity in human [4]. CGA have antiinflammatory, anticancer, antidiabetic, antimicrobial, hepatoprotective, neuroprotective, cardioprotective and lipid lowering properties [5-8]. Our study confirmed that CGA enriched green coffee treatment ameliorated renal injury [9]. Several comprehensive reviews have also been available on risk and benefit of coffee consumption $[10,11]$.

${ }^{*}$ Corresponding author: Avijit Saha

Associate Professor, Department of Biochemistry, R.G. Kar Medical College, Kolkata, India.

Copyright $(2021$ Author(s) retain the copyright of this article. This article is published under the terms of the Creative Commons Attribution Liscense 4.0. 
<smiles>O=C(/C=C/c1ccc(O)c(O)c1)O[C@H]1C[C@@](O)(C(=O)O)C[C@H](O)[C@H]1O</smiles>

Figure 1 Empirical structure of Chlorogenic acid

Although, natural compounds of coffee seeds have been distorted or reduced during the process of decaffeination, stream treatment, roasting processed to produce instant coffee. Sophisticated analytical methods, like high performance liquid chromatography (HPLC), gas chromatography (GC) and capillary electrophoresis (CE) have been developed for the determination of non-volatile, volatile, polar and non-polar classes of compounds in coffee [12]. As the health benefit of coffee consumption mainly depends on its major active constituent, namely on CGA and its derivatives, hence standardization of coffee would like to be focused on the amount of CGA present in different form of coffee. In this regards, we developed and validated a simple and cost effect chromatographic technique to identify and quantify CGA in green coffee, roasted coffee and branded instant coffee available in Indian market.

\section{Material and methods}

\subsection{Test samples preparation}

Two different forms of coffee bean (seeds) - green and roasted coffee seed; and two branded instant coffee - Nescafe (Nestle, India) and BRU Coffee (Hindustan Unilever Ltd, India) were used. The green and roasted coffee bean seeds were made in coarse powder by electric grinder. The powder was merged in 60-40 methanol-water (v/v) at a solvent/solid ratio of $40 \mathrm{ml} / \mathrm{g}$ for $90 \mathrm{~min}$ at room temperature [13]. Two branded instant coffee, Nescafe and BRU Coffee were dissolved in $60 \%$ methanol water.

\subsection{UV-vis spectroscopic analysis}

All test samples were further diluted into different concentrations $(100-500 \mu \mathrm{g} / \mathrm{ml})$ and scan in spectrophotometer (UV-1800 Shimadzu, Japan) at 200-400 $\lambda$ [14]. The standard curve of chlorogenic acid (Sigma, USA) at different known concentration (5-9 mg/L) was performed and plotted as absorbance vs. concentration. The concentrations of CGA present in test samples were calculated against standard curve of CGA.

\subsection{High performance thin layer chromatographic method}

Presence of chlorogenic acid in test samples was determined using densitometric HPTLC technique. The reference standard chlorogenic acid (Sigma-Aldrich, USA) was dissolved in methanol at the concentration of $1 \mathrm{mg} / \mathrm{ml}$ and applied $200 \mathrm{ng}, 300 \mathrm{ng}$, $400 \mathrm{ng}, 500 \mathrm{ng}$, and $600 \mathrm{ng}$ to prepare the standard calibration curve (peak height and area) by plotting peak areas versus concentration. The Rf of CGA was 0.35 . The accuracy of method has been verified.

Table 1 Instrumental and chromatographic conditions.

\begin{tabular}{|l|l|l|l|}
\hline Instrument & CAMAG Linomat 5 & Slit dimensions & $\mathbf{5} \mathbf{X ~ 0 . 4 5 ~} \mathbf{\mu m}$ \\
\hline Detector & CAMAG TLC Scanner 3 & Brand length & $8 \mathrm{~mm}$ \\
\hline Soft-ware Analysis & winCATS Planar & Pre-dosage volume & $0.2 \mu \mathrm{l}$ \\
\hline Calibration mode & Multi level & Application volume & $2-10 \mu \mathrm{l}$ \\
\hline Evaluation mode & Peak height \& Area & Lamp & D2 \\
\hline Stationary phase & $\begin{array}{l}\text { HPTLC plates Silica gel 60 F 254 } \\
\text { (E.MERCK KGaA) }\end{array}$ & Mobile phase & $\begin{array}{l}\text { EA: DCM: FA: AA: DW= } \\
10: 2.5: 1: 1: 1.1\end{array}$ \\
\hline Plate size & $20.0 \times 10.0 \mathrm{~cm}$ & Wavelength & $330 \mathrm{~nm}$ \\
\hline
\end{tabular}

The test samples were spotted in the form of bands on a pre-coated silica gel plates (E. Merck, 60F $254,20 X 10 \mathrm{~cm}$ ) $\mathrm{using}$ CamagLinomat 5 applicator (Camag, USA). The plates were developed in ultrapure solvent system containing ethyl 
acetate: dichloromethane: formic acid: acetic acid: water $=$ 10:2.5:1:1:1.1 in Camag glass chamber and air dried for 5 min at $60^{\circ} \mathrm{C}$. The densitometric scanning was performed on Camag TLC Scanner 3, operated by multi-level winCATS planar chromatography manager at absorbance $330 \mathrm{~nm}$ (Table 1). The amount of chlorogenic acid present in test samples were auto-generated against standard curve $[15,16]$.

ICH guidelines were followed for the method validation of the analytical procedures [17]. The method was validated for precision, repeatability and accuracy. The repeatability of the method was checked by repeated scanning of the same spot of chlorogenic acid (300 ng), six times and was expressed as co-efficient of variance (\% CV). The variability of the method was studied by analyzing aliquots of chlorogenic acid (as $200 \mathrm{ng}, 400 \mathrm{ng}$ and $600 \mathrm{ng}$ ) on the same day and on different days and the outcome data were expressed as \% CV. The recovery studies were done at three levels $(50 \%$, $100 \%$ and $150 \%$ addition). The percent recovery and average percent recovery was calculated for studying accuracy of method.

\subsection{Statistical analysis}

Descriptive data were presented as mean and standard deviation. A p-value of less than 0.05 was considered statistically significant.

\section{Results and discussion}

Chlorogenic acid (CGA) was discovered in 1837 and International Union of Pure and Applied Chemistry (IUPAC) recommended 5-caffeoylquinic acid (5-CQA) or chlorogenic acid in the year 1908 [18,19]. The empirical structure of CGA is given in Fig. 1. Adequate amount of CGA is present in tobacco leaves, mulberry tree and coffee beans. It is found to be responsible for the astringent taste of coffee brews [20]. The biological activities of CGA are now well documented. During the process of decaffeination, roasting, extraction, blending and brewing some volatile constituents including CGA have been altered. The content of CGA (including their lactones) in coffee mostly vary from $26 \mathrm{mg}$ to $1141 \mathrm{mg}$ per $100 \mathrm{ml}$ [21-22]. In general, considering the different existing brewing methods the values reported for major CGA in brews prepared at 6\%-17.5\% [23]. Thus it is essential to distinguish the amount of CGA present in different forms of coffee. Unfortunately, there are no simple and cost effective methods for the detection of CGA. Usually, HPLC, GC and capillary electrophoresis are used to assess CGA. In this context, two simple detection procedures for CGA in different forms of coffee samples were trying to establish.

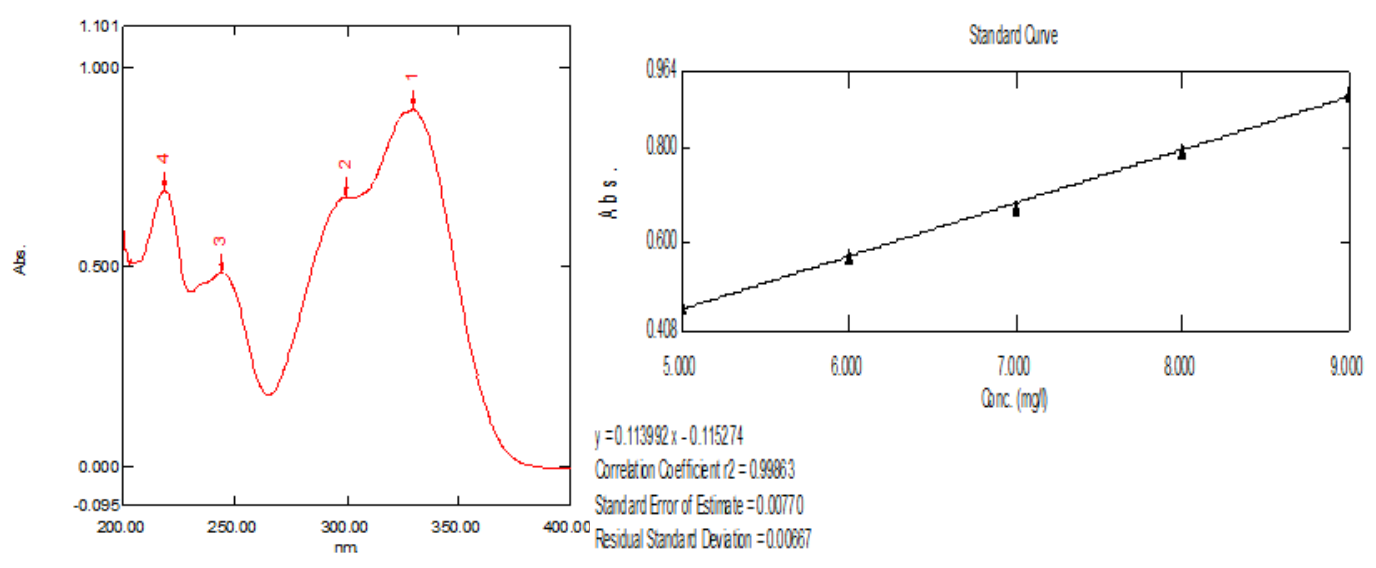

Figure 2 UV-VIS spectrum of CGA standardFigure 3 UV-VIS standard curve of CGA

The UV-Vis spectrums of scanning of all four test samples are presented in Fig. 4. The content of CGA in test samples were derived from the standard curve, which is $5.3 \%$ in crud green coffee seed, $2.33 \%$ in roasted coffee seed, $31.16 \%$ in Nescafe and $20.53 \%$ in BRU coffee (Table 2). 


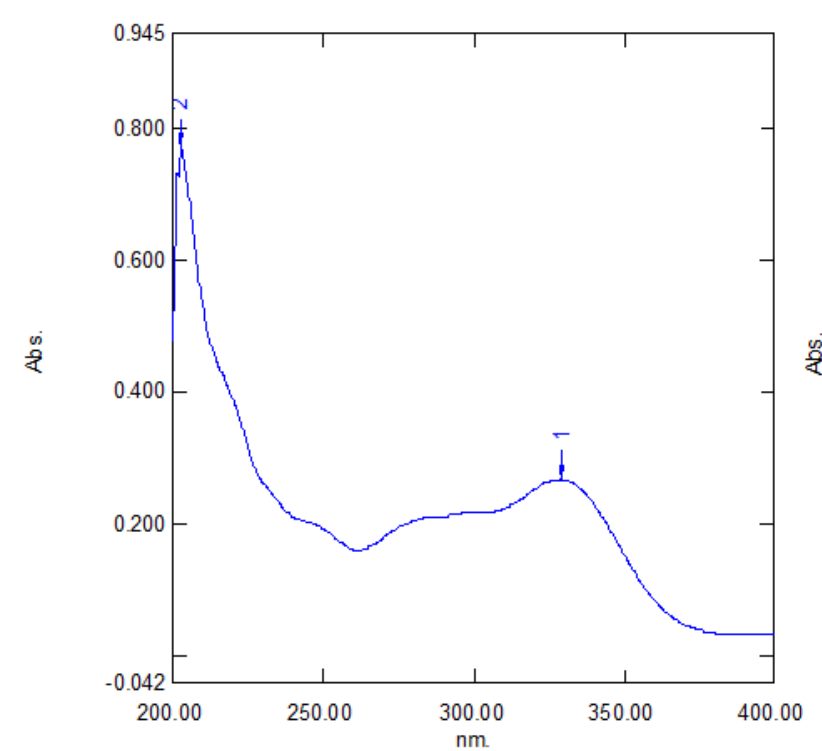

Green coffee seed

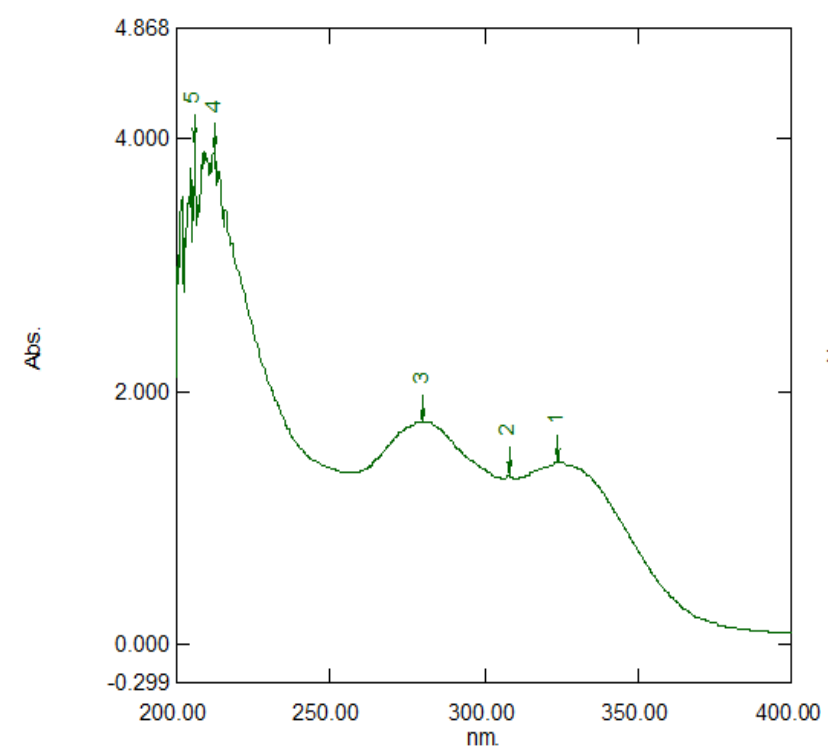

Nescafe (Instant coffee)

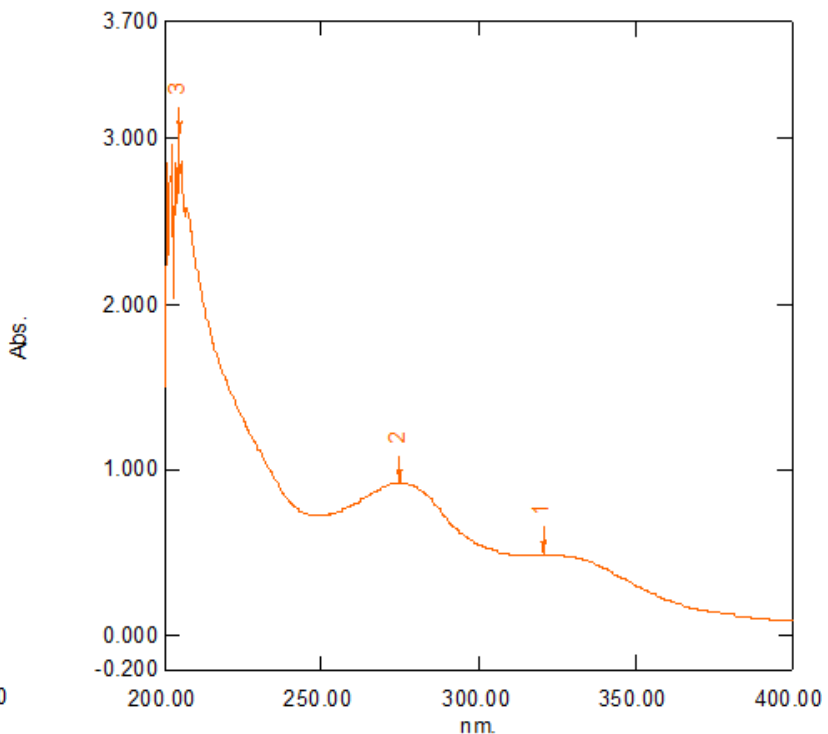

Roasted coffee seed

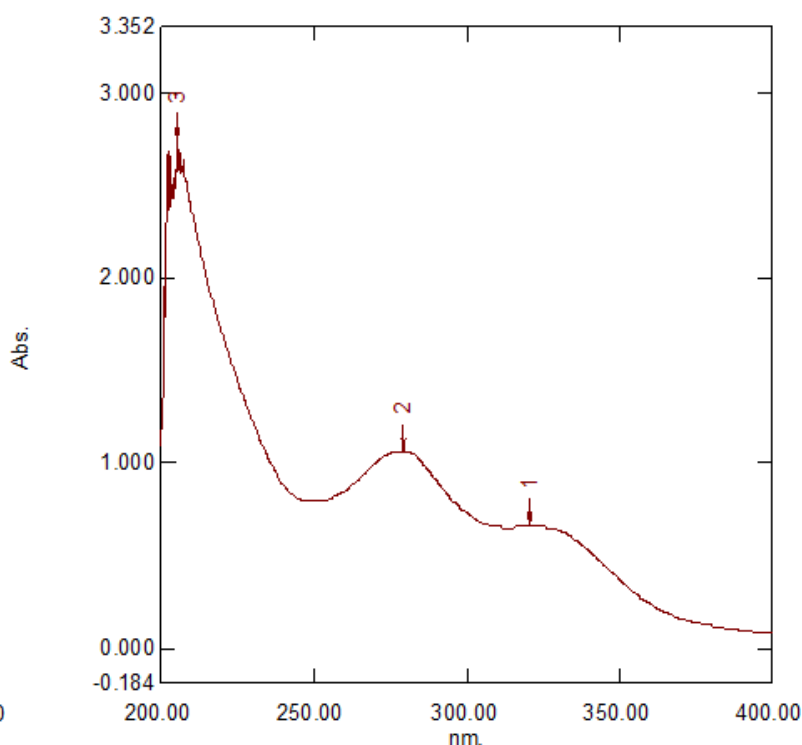

BRU coffee (Instant coffee)

Figure 4 UV-Vis spectrum of coffee samples

The practice of HPTLC is well acceptable all over the world as it remains most flexible, reliable, reproducible and costeffective separation technique for the analysis of food, botanicals and herbal drugs [16, 24].

In the present study, the HPTLC technique was optimized with a view to develop a stability indicating assay method [9]. The solvent system of the mobile phase having ethyl acetate: dichloromethane: formic acid: acetic acid: water $(10: 2.5: 1: 1: 1.1, \mathrm{v} / \mathrm{v})$ gave dense, compact and well separated spots of coffee samples at $330 \mathrm{~nm}$. The limit detection for CGA and the limit of quantification was found to be $20 \mathrm{ng} / \mathrm{ml}$ and $800 \mu \mathrm{g} / \mathrm{ml}$ respectively. The $\mathrm{R}_{\mathrm{f}}$ value of CGA was noted 0.35 (Fig. 5). The calibration curve of CGA was linear over the concentration range 100-600 ng per spot and regression was $r=0.98858$ (Fig. 6). 


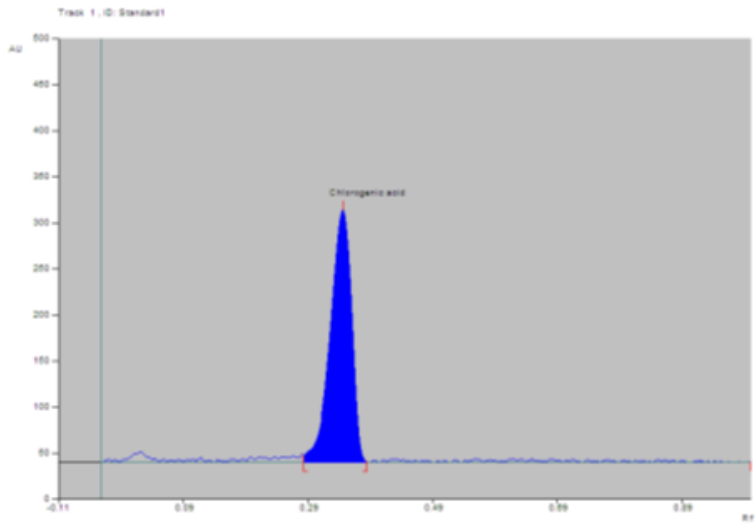

Figure 5 HPTLC chromatogram of CGA

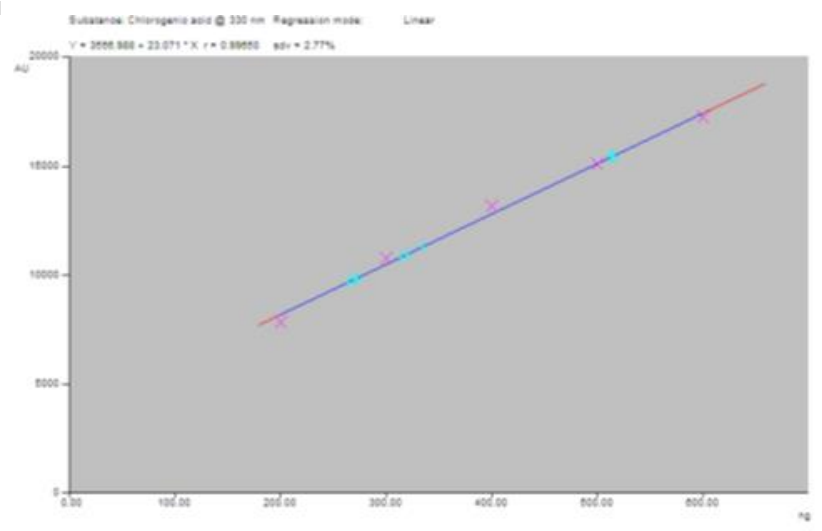

Figure 6 HPTLC standard curve of CGA

The presence of CGA in the HPTLC chromatograms of all test coffee samples was matched with known standard of CGA at Rf 0.35 when scan at $330 \mathrm{~nm}$ (Fig. 7-10). The HPTLC chromatogram of instant Nescafe represented well separated and prominent 11 characteristic bands, while instant BRU coffee showed only 8 less prominent bands, which clearly point out the nature of compounds other than CGA, are contrary in instant coffee samples. On the hand, nature of the compounds present in the HPTLC fingerprint of green coffee seeds was changed after roasting the coffee seeds that may be due to breakdown of CGA into derivatives or due to loss of moisture present on seeds. Table 2, represented the amount of CGA in different form of coffee samples. The ranges of CGA presents in different form of coffee samples were vary from $22.41 \mathrm{mg} / \mathrm{g}$ to $358.35 \mathrm{mg} / \mathrm{g}$. The maximum amount of CGA was present in instant Nescafe (35.8\%) followed by instant BRU coffee (22.9\%), green coffee seed (6.45\%) and roasted coffee seeds $(2.24 \%)$.

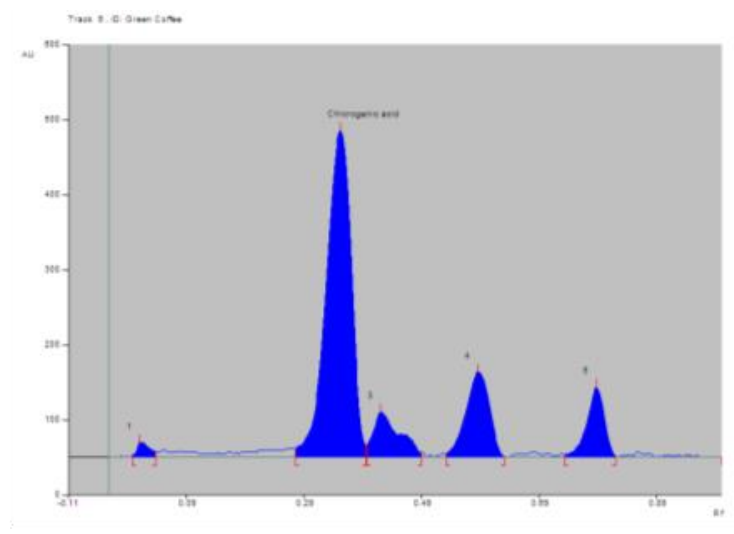

Figure 7 CGA in Green Coffee Seed

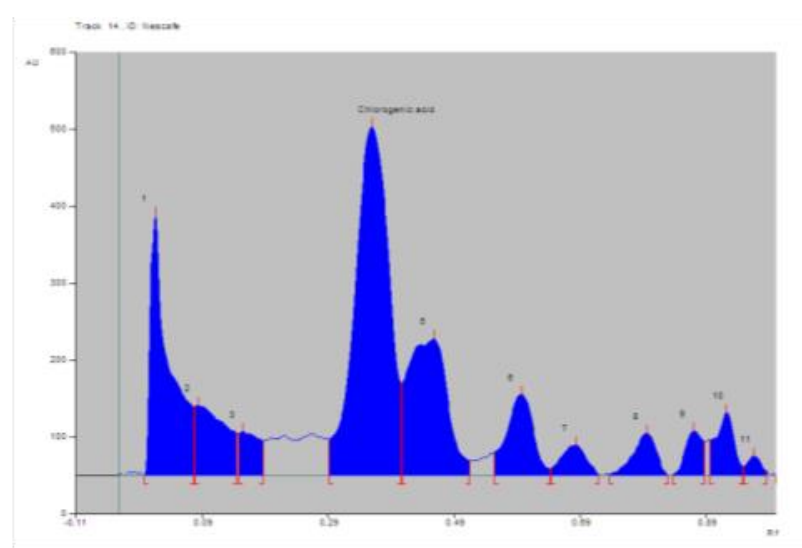

Figure 9 CGA in Nescafe (Instant coffee)

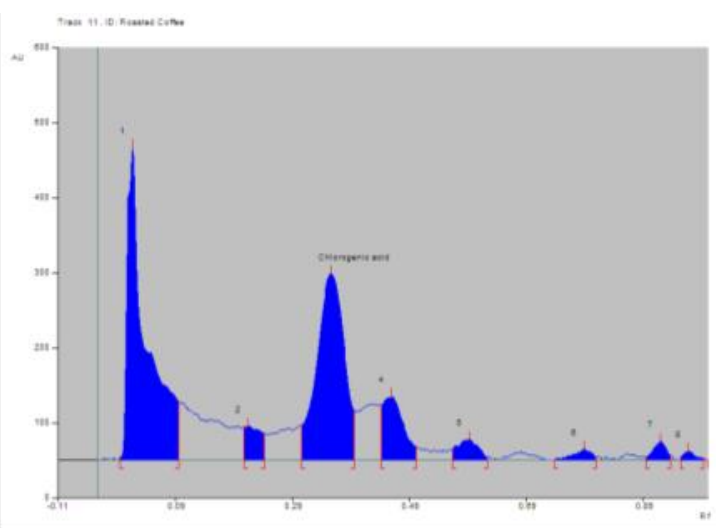

Figure 8 CGA in Roasted coffee seed

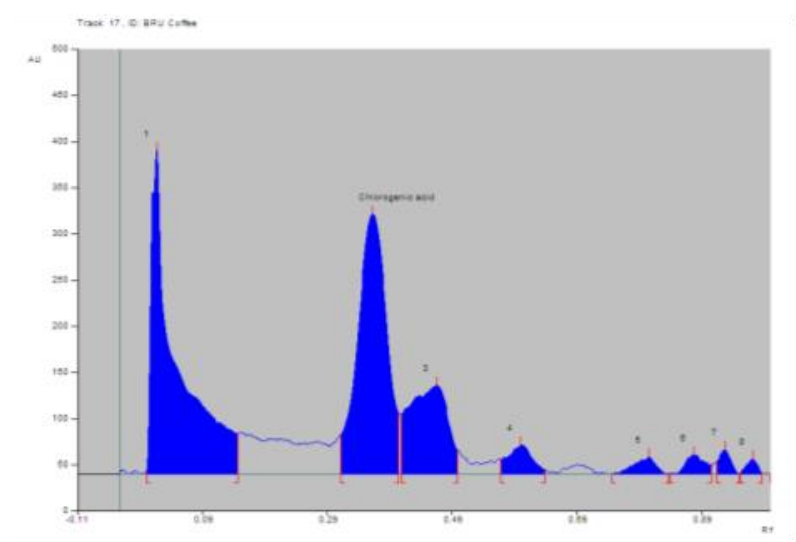

Figure 10 CGA in BRU Coffee (Instant coffee) 
Table 2Estimation of CGA by UV-Vis Spectroscopy and HPTLC.

\begin{tabular}{|l|l|l|}
\hline & Chlorogenic acid (CGA) \\
\hline & UV-Vis Spectroscopy & HPTLC \\
\hline Green coffee seed & $53.08 \pm 1.04$ & $64.58 \pm 0.17$ \\
\hline Roasted coffee seed & $23.29 \pm 1.01$ & $22.41 \pm 0.32$ \\
\hline Nescafe (Instant coffee) & $311.62 \pm 3.26$ & $358.35 \pm 3.61$ \\
\hline BRU coffee (Instant coffee) & $205.33 \pm 2.24$ & $229.14 \pm 3.45$ \\
\hline \multicolumn{2}{|l|}{ N=6 in each test; mean \pm standard deviation; unit $=\mathrm{mg} / \mathrm{g}$} \\
\hline
\end{tabular}

Furthermore, comparisons between two separate analytical methods i.e., UV-Vis- spectral analysis and HPTLC clearly revealed that HPTLC method is more sensitive and reliable to detect CGA in coffee samples than other one.

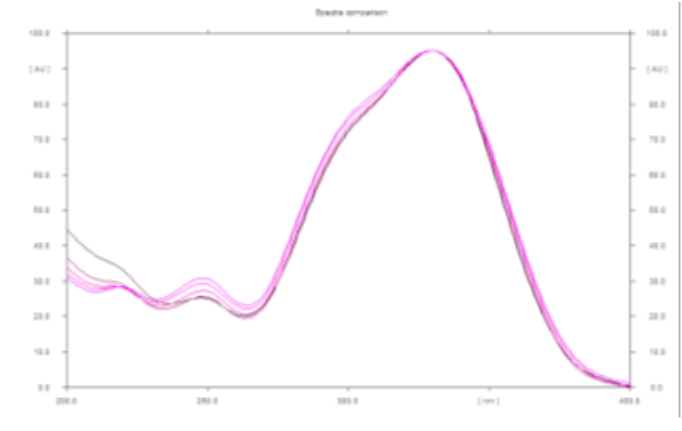

Figure 11 HPTLC spectrum of CGA standard

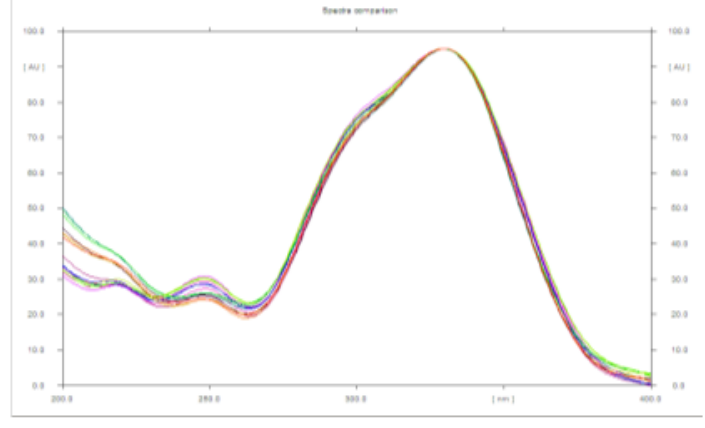

Figure 12 Integrated spectrum of CGA standard and test samples

Whilst reliability for detection of CGA by presently developed HPTLC method was confirm with the integrated spectra of all concentrations of standard CGA and different coffee samples (Fig 11-12). Thus, the method was found to be accurate, precise, suitable and cost effective for the estimation of chlorogenic acid (CGA) in any form of coffee samples.

\section{Conclusion}

This HPTLC method can be successfully employed for standardization and quantitative analysis of chlorogenic acid (CGA) in any forms of coffee as well as foods, herbs, phytochemicals and pharmaceuticals containing CGA.

\section{Compliance with ethical standards}

\section{Acknowledgments}

The authors would like to thanks Dean, RKMVERI and Principal, R.G. Kar Medical College for proving their permission and facilities of the present work.

\section{Disclosure of conflict of interest}

The authors declare that there is no conflict of interest.

\section{References}

[1] Farah A. Coffee: Production, quality and chemistry. Cambridge: Royal Society of Chemistry. 2012.

[2] Nuhu AA. Bioactive micronutrients in coffee: recent analytical approaches for characterization and quantification. ISRN Nutrition. 2014; 384230. 
[3] Farah A, Monteiro M, Donangelo CM, Lafay S. Chlorogenic acids from green coffee extract are highly bioavailable in humans. J Nutrition. 2008; 138:2309-2315.

[4] Revuelta-Iniesta R, Al-Dujaili EAS. Consumption of green coffee reduces blood pressure and body composition by influencing $11 \beta$-HSD1 enzyme activity in healthy individuals: a pilot crossover study using green and black coffee. BioMed Res Int. 2014;482704.

[5] Upadhyay R, Rao LJM. An outlook on chlorogenic acids: occurrence, chemistry, technology, and biological activities. Critical Rev Food Sci Nutrition. 2013; 53:968-984.

[6] Xu JG, Hu QP, Liu Y. Antioxidant and DNA-protective activities of chlorogenic acid isomers. J Agric Food Chem. 2012; 60:11625-11630.

[7] Baeza G, Amigo-Benavent M, Sarria B, Goya L, Mateos R, Bravo L. Green coffee hydroxycinnamic acids but not caffeine protect human HepG2 cells against oxidative stress. Food Res Int. 2014; 62:1038-1046.

[8] Arfian N, Wahyudi DAP, Zulfatina IB, Citta AN, Anggorowati N, Ali M, Romi R, Sari DCR. Chlorogenic acid attenuates kidney ischemic/reperfusion injury via reducing inflammation, tubular injury and myofibroblast formation. BioMed Res Int. 2019; 5423703.

[9] Bhattacharyya S, Kumar R, Sengupta A, Hazra AK, Sur TK. Chlorogenic acid enriched green coffee ameliorated renal injury in rats. Mymensingh Med J. 2020; 29:991-1000.

[10] Pourshahidi LK, Navarini L, Petracco M, Strain JJ. A comprehensive overview of the risks and benefits of coffee consumption. Comprehensive Rev Food Sci Food Safety. 2016; 15.

[11] Farah A, Lima JP. Consumption of chlorogenic acids through coffee and health implications. Beverages. 2019; $5: 11$.

[12] Belay A. Some biochemical compounds in coffee beans and methods developed for their analysis. Int J Physical Sci. $2011 ; 6: 6373-6378$.

[13] Mussatto SI, Ballesteros LF, Martins S, Teixeira JA. Extraction of antioxidant phenolic compounds from spent coffee grounds. Sep Puri Tech. 2011; 83:173-179.

[14] AOAC: Association of Official Analytical Chemists. Coffee and Tea. In: Official methods of analysis. 17th ed. Gaithersburg, Md.: AOAC. 2000.

[15] Urakova IN, Pozharitskaya ON, Shlkov AN, Kosman VM, Makarov VG. Comparison of high performance TLC and HPTLC for separation and quantification of chlorogenic acid in green seed extracts. J Sep Sci. 2008; 31:237-241.

[16] Hazra AK, Chakraborty B, Mitra A, Sur TK. A rapid HPTLC method to estimate piperine in Ayurvedic formulations containing plant ingredients of Piperaceae family. JAIM. 2019; 10:248-254.

[17] ICH guideline: The International Council for Harmonisation of Technical Requirements for Pharmaceuticals for Human Use. 2020.

[18] IUPAC. Nomenclature of cyclitols. Biochem J. 1976; 153:23-31.

[19] Kremr D, Bajer T, Bajerova P, Surmova S, Ventura K. Unremitting problems with chlorogenic acid nomenclature: A review. Quim Nova. 2016; 39:530-533.

[20] Moon JK, Yoo HS, Shibamoto T. Role of roasting conditions in the level of chlorogenic acid content in coffee beans: correlation with coffee acidity. J Agri FoodChem. 2009; 57:5365-5369.

[21] Tfouni SAV, Carreiro LB, Teles CRA, Furlani RPZ, Cipolli KMVAB, Camargo MCR. Caffeine and chlorogenic acids intake from coffee brew: Influence of roasting degree and brewing procedure. Int J Food Sci Technol. 2014; 49:747-752.

[22] Ludwig IA, Mena P, Calani L, Cid C, Del Rio D, Leand MEJ, Crozier A. Variations in caffeine and chlorogenic acid contents of coffees: What are we drinking? Food Funct. 2014; 5:1718-1726.

[23] Jeon JS, Kim HT, Jeong IH, Hong SR, Oh MS, Park KH, Shim JH, Abd El-Aty AM. Determination of chlorogenic acids and caffeine in homemade brewed coffee prepared under various conditions. J Chromatogr B Anal Technol Biomed Life Sci. 2017; 1064:115-123.

[24] Attimarad M, Ahmed KKM, Aldhubaib BE, Harsha S. High-performance thin layer chromatography: A powerful analytical technique in pharmaceutical drug discovery. Pharm Methods. 2011; 2:71-75. 